\title{
MULTICRITERIA DECISION AIDED SYSTEM FOR RANKING INDUSTRIAL ZONES (RPRO4SIGZI)
}

\author{
AissaTaibi, BaghdadAtmani \\ Laboratoire d'Informatique d'Oran - LIO \\ Université d'Oran 1 Ahmed Benbella \\ taibiissa@yahoo.fr \\ atmani.baghdad@gmail.com
}

\begin{abstract}
Integration of Geographic Information Systems (GIS) and multi-criteria decision analysis $(M C D A)$ is a privileged and indispensable way to evolve GIS into real decision support systems. RPRO4SIGZI, the system proposed in this paper allows, from a detailed study of geographical, environmental and socioe-conomic criteria to cooperate GIS and multi-criteria decision analysis method for spatial choosing of the right site for installing industrial projects. The result obtained by RPRO (Ranking PROMETHEE) for ranking industrial zones in western Algeria is refined by a viewing SIGZI (Geographic Information System for Industrial Zones). The RPRO unit rank industrial zones using the outranking PROMETHEE II method issue from European school and SIGZI module to the visualization of these zones on the map. RPRO4SIGZI system was designed for the evaluation of a new methodology of multi-criteria analysis guided by data mining. The objective is to show how data mining is used to model the preferences of the decision maker tainted with subjectivity and hesitance to generate suitable performance tables. Only RPRO4SIGZI system is presented in this paper.
\end{abstract}

\section{KEYWORDS}

Geographic Information System (GIS), multi-criteria decision analysis (MCDA), Industrial Zones, MCDA-GIS integration, Cartography, PROMETHEEII.

\section{INTRODUCTION}

The geo-decisional study of zonal aptitude for selecting the location of new housing sites, industries and services is essential and is a real spatial decision problem. Policy makers should act early based on depth analysis of the environmental, socioeconomic and other criteria (factors, constraints) to carefully carry out their decisions to end without risks. This work is to rank the industrial zones of western Algerian using the outranking method PROMETHEE II [1]. It follows a preliminary choice based on a zonal aptitude analysis using non-compensatory Aggregation methods. Each zone is a space action since action to take is spatial if it is defined by its geographical location, shape and spatial relations [2]. Most judgment criteria have a geographical character. The specifics of this kind of problems is in favor of integration between GIS and

David C. Wyld et al. (Eds) : DBDM, CICS, CSIP, AI\&FL, SCOM, CSE, CCNET-2016

pp. 11-27, 2016. () CS \& IT-CSCP 2016

DOI : $10.5121 /$ csit.2016.60502 
MCDA where the adoption of this approach. The researchers focused on this approach since 1999, hundreds of articles have been published [3]. The conceptual idea on which is based MCDA-GIS integration work is to use the functions of GIS to prepare inputs necessary for the MCDA methods and GIS presentation potentialities to visualize the results of the analysis on the map [4]. In literature there are many definitions for GIS, a coherent definition with this study is that of Marc Souris [5]: "A geographic information system (GIS) is primarily a database management system capable of managing localized data, and therefore able to capture, store, extract (especially on geographical criteria) to query and analysis, and finally to represent and map. The displayed objective is essentially for synthesizing, and allowing data management as decision support". The input for the PROMETHEE II method is a performance table which contains values (score) for each action (industrial zone) relative to the set of criteria plus the additive information about criteria necessary to use this method.

Evaluation of an action relative to geographic criteria is based on an important feature of GIS: Mapping, this discipline is the first step of spatial analysis; a map is a model of reality that contains the geometric representation of objects and categories of objects with graphical and semiotic logic [6]. For example the seismic value of a zone derives from its geographical position on the seismic map of Algeria. As a result of total ranking, the best zone is obtained with visualization on map before and after ranking. The adoption of GIS-MCDA approach in this case has confronted us several problematic such as the choice of the appropriate MCDA method? The subjectivity and hesitance of decision makers? ... To solve the second problem we will engage data mining to model the preferences of the decision maker and generate performance tables. The rest of this article is presented as follows. Section 2 is devoted to the problem and some related works, Section 3 and 4 is devoted to the GIS-MCDA approach and PROMETHEE II method, the proposed model is in section 5, a case study is illustrated in section 6 , we end with a conclusion and perspectives.

\section{Problematic AND Related WORK}

Problems related to the evolution of urban fabric, building new cities, and creation of new industrial zones is analysis problems of zonal aptitudes in a larger context of decision support. The spatial decisional study of zonal aptitude to select the location of new housing sites, industries and services is essential and is a real problem of spatial decision. Anarchic zoning to solve such problems can cause epidemiological change and deterioration in the health of citizens. The linear model of Simon and its extensions are insufficient to respond to the complexity of these problems [7]. Geographic information systems (GIS) are important for the analysis of decision problems where the geographic components of the data are considered. GIS is primarily an explanatory help tool for decision. Multi-criteria decision analysis methods MCDA provides the techniques necessary to structure and evaluate alternatives in decision-making problems according to defined set of criteria and proposed weighting. GIS research areas and multi-criteria decision analysis methods for decision aids are distinct but they help each other to get the best spatial decision problems solutions.

MCDA-GIS integration works have increased since 1990. Most of this work since 1990 until 2004 were identified and categorized in [3]. In [8] there is recognition of the variety and complexity of multi-criteria analysis methods, to remedy this, the authors have made scanning and classification of all methods. The classification leads to the following classes: 
- Non-compensatory Aggregation methods

- Weighting methods (AHP...)

- Compensatory aggregation methods

- Outranking methods (ELECTRE, PROMETHEE ...)

- Mathematical Programming Method.

- Heuristic methods (MOLA, GA, SA ...)

More recent work as in [9] where comparing AHP and PROMETHEE II for selecting best techniques used in building conclude that PROMETHEE II is the appropriate method since its results are consistent, easy to understand and requires less information from decision makers . In [10] the objective was to estimate the ecological values of the Piedmont region of northern Italy and generate maps for use as assistance with the decision variables in the field of planning and land management to protect environment and echo systems. In [11] the purpose was to find a suitable geography to lay the vegetable water (waste water from the olive crushing). In [12] the objective is to measure the vulnerability of forest habitat interfaces, the authors used the AHP method (SAATY, 1980) to treat six decision criteria (layout, topography, vegetation structure, habitat structure, properties of buildings, socio-economic structures). They proceeded to map the vulnerability of each criterion by using ARCGIS. In [13] the goal is to alleviate the dissatisfaction of some group of citizens in Quebec when planning a linear park section of less than $15 \mathrm{~km}$ from the new port area of Quebec. Another work that is within the scope of energy diversification is to design a MCDA-GIS model to guide a project on wind energy in Canada [14].

\section{THE INTEGRATION BETWEEN GIS AND MCDA}

Spatial decision problems constitute a large part of decision-making problems. This type of problems is characterized by geographic data with spatial attributes (coordinates, shape...). Spatial problems whose complexity is related to the heterogeneity of data and concepts mobilized to model the geographical reality often have a multi-criteria aspect [2] .The complexity of these problems comes from (i) the multidimensional and interdisciplinary nature which is difficult to formalize, (ii) the involvement of several persons and institutions, generally with preferences and diverging objectives, (iii) the need to define multiple conflicting criteria whose importance is not the same [4]. The solution of such problems generates a spatial multi-criteria decision. Most of the involved geographical criteria must be mapped for decision makers. Alternative also, must be mapped and displayed. The spatial multi-criteria analysis for decision aid (SMADA) needs spatial and descriptive data both for imposed criteria and considered alternatives. All data are processed and aggregated in one hand by the MCDA using appropriate decision rules and by GIS for spatial analysis and mapping in the other hand, therefore the two tools are used interchangeably [3]. The conceptual idea on which the GIS-MCDA integration is based is to use the capabilities of GIS to prepare inputs necessary for the implementation of a multi-criteria method and exploit the potential of GIS for presentation to see the results of the analysis on maps [4]. Below some arguments in favor of the integration or coupling [4], [3], [2].

- To solve a spatial decision problem we need to consider both spatial and decision components problem.

- GIS is well suited for the representation of decision problems with spatial reference but it fails to take into account the multi-criteria decision dimension of the problem. 
- MCDA allows formulation and modeling of spatial problems but it is limited to represent the spatial dimension of this problem.

GIS-MCDA approach is applied with a rate of $72.4 \%$ in the field of territorial and environmental management, transport, urban planning, waste management areas, hydrology and agriculture. $30 \%$ of treated decisional problems involve susceptibility or suitability analysis [3]. Among the questions related to the approach there is the lack of a related maintenance policy, absence of correlation between the problem, the aggregation rule and GIS. There is also an ambiguity related to the integration mode of the two tools. [4] Has proposed three integration mode (a: Indirect Integration, b: Built Integration, c: Complete integration).

In this paper a mixed integration is proposed, preparing geographic criteria to establish performance table is made by SIG independently (indirect integration) while visualizing function is integrated directly with the MCDA Module and is considered as a finality of the decision analysis (figure 1).

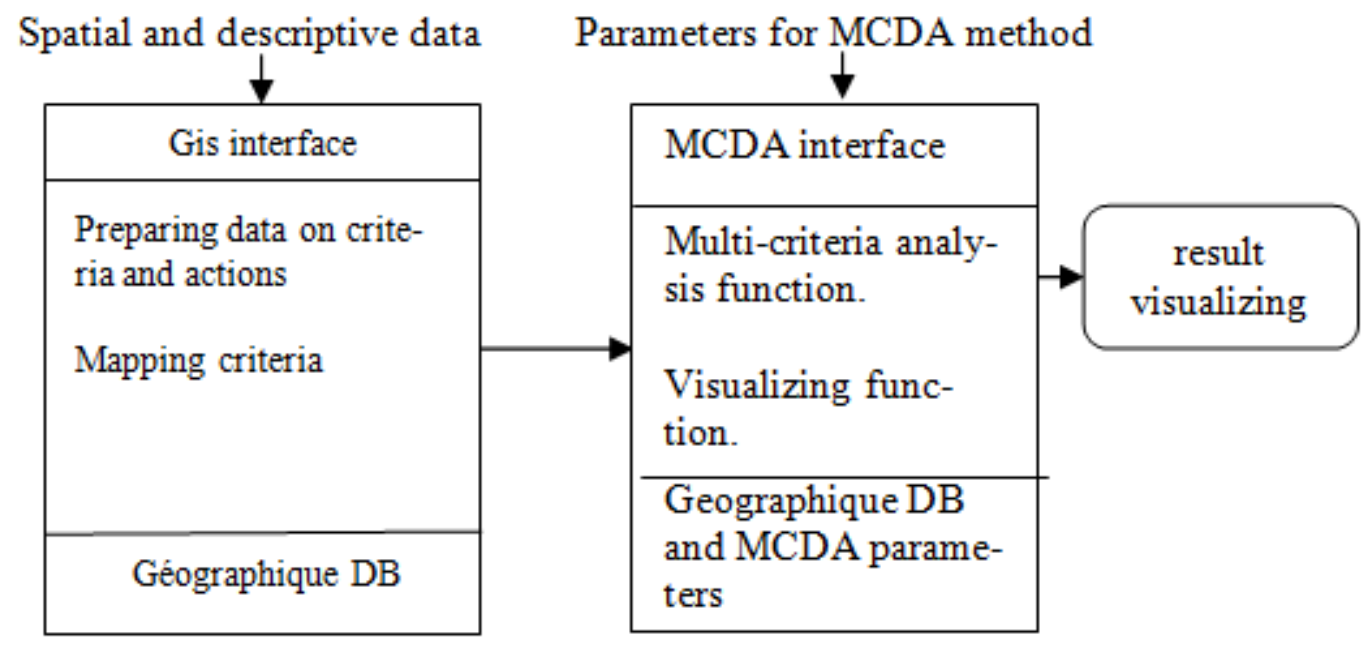

Figure 1. GIS-MCDA proposed integration.

\section{PROMETHEE}

PROMETHEE I method for partial ranking and PROMETHE II for total ranking were developed by JP Brans in 1982. Other extensions, PROMETHEE III and PROMETHEE IV and the GAIA interactive graphics module of this methodology were developed later. PROMOTHEE is successfully used in the fields of industrial location, investments, medicine and chemistry ... Its success returns to its user-friendly and there mathematical properties [1],[15] . It is an outranking method [18] based on dominance relationships among alternatives against criteria associated to a multicriteria problem (P: Preference I: indifference, R: In comparability): 


$$
\begin{aligned}
& \left\{\begin{array}{l}
\forall \mathrm{j}: \mathrm{g}_{\mathrm{j}}(a) \geq \mathrm{g}_{\mathrm{i}}(\mathrm{b}) \\
\exists k: g_{k}(a)>g_{k}(b)
\end{array}\right. \\
& \forall \mathrm{j}: \mathrm{g}_{\mathrm{j}}(a)=\mathrm{g}_{\mathrm{i}}(\mathrm{b}) \\
& \left\{\begin{array}{l}
\exists \mathrm{s}: \mathrm{g}_{s}(a)>\mathrm{g}_{s}(\mathrm{~b}) \\
\exists_{r}: g_{r}(a)<g_{r}(b)
\end{array} \longrightarrow a I b\right.
\end{aligned}
$$

$\mathrm{g}_{\mathrm{j}}(\mathrm{a})$ denotes the evaluation of action a under criterion $\mathrm{j}$.These relationships create a dominance graph. An appropriate multicrititeria analysis method wish to enrich this graph, since the objective is to reduce the number of in-comparabilitys in order to optimize the decision. Consideration of in-comparabilitys is an asset because it reflects reality. Reduce the number of in-comparabilitys does not mean elimination of them . Other assets of PROMETHEE according to its inventor J.P. Brans [15] reside in the following requirements:

R1: The amplitude of the deviations between the alternatives within criterions is taken into account. It is denoted by:

$$
\mathrm{d}_{\mathrm{j}}(a, b)=g_{i}(a)-g_{j}(b)
$$

When $d_{j}$ is negligible, dominance relation can be enriched by other means.

R2: $g_{i}(a)$ is expressed with its own measurement unit, scale effects should be eliminated because it is not acceptable to obtain conclusions with scaling effects upon which the evaluations are expressed.

R3: The binary comparisons provide all possible information on the two compared alternatives (a is preferred then $b, a$ and $b$ are indifferent, $a$ and $b$ are incomparable). The purpose is of course to reduce as much as possible the number of incomparability, but not when it is not realistic.

R4: The method must be understandable by the decision-makers. "Black box" procedures should be avoided.

R5: The technical parameters which have no significance for the decision maker must be rejected.

R6: An appropriate MCDA method must provide information about the confrontational nature of the criteria.

R7: The MCDA methods use the relative importance of the criteria through weights given by the decider tainted by his subjectivity and hesitation. A method that respects itself provides tools for the study of sensitivity.

In addition to the performance table necessary to the outranking methods , PROMETHEE requires two clear information, easy to find and assimilated by the decision maker for the best compromise solution : 


\subsection{Information among the criteria}

Described by the set $\left\{w_{j} / \mathrm{j}=1 \ldots \mathrm{k}\right\}$ of relative importance weights for different criteria. These are positive numbers independent of units of measurement with $\sum w_{j}=1$. The decision maker is free to give these weights tainted with his hesitation and his subjectivity. If these notes are arbitrary they must be normalized by dividing each weight by the sum of all the others.

\subsection{Information on the criteria}

PROMETHEE uses the difference between the evaluation of two alternatives $a$ and $b$ on any criterion $\mathrm{j}$ as in equation (4) to build a preference structure, this gap $\left(\mathrm{d}_{\mathrm{j}}\right)$ is reversed if the criterion is to minimize, cost criteria for exemple. The degree of preference is proportional to the degree of the gap, the preferences are measured by real numbers between 0 and 1 . In the mind of the decision maker's preference between two alternatives $a$ and $b$ is a function of the gap $d_{j}$ that is expressed mathematically by:

$$
\begin{array}{lll}
\mathrm{P}_{\mathrm{j}}(a, b)=\mathrm{F}_{\mathrm{j}}\left[d_{j}(a, b)\right] & (5) & \text { If the criteria is to maximize } \\
\mathrm{P}_{\mathrm{j}}(a, b)=\mathrm{F}_{\mathrm{j}}\left[-d_{j}(a, b)\right] & \text { (6) } & \text { If the criteria is to minimize }
\end{array}
$$

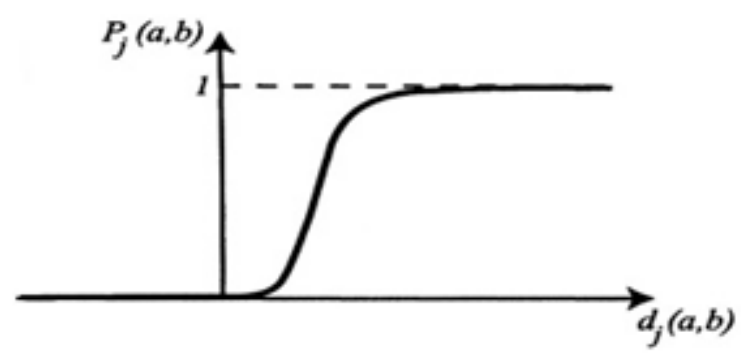

Figure 2 : Preference function [1]

The couple $\left\{g_{j}(),. P_{j}(\mathrm{a}, \mathrm{b})\right\}$ is the generalized criterion associated to $g_{j}($.$) criterion. It is the$ concept of generalization that characterizes PROMETHEE compared to other outranking methods. The generalized criterion function associated with preference, indifference and intermediate thresholds provides six types of preference functions. The behavior of each action overlooked to the others is enjoyed by three flows:

$$
\begin{array}{ll}
\text { The positive flow: } & \varphi^{+}(a)=\sum_{x \in A} \pi(x, a) \\
\text { The negative flow : } & \varphi^{-}(a)=\sum_{x \in A} \pi(a, x) \\
\text { The net flow : } & \varphi(a)=\varphi^{+}(a)-\varphi^{-}(a)
\end{array}
$$

The preference index for an alternative a compared to another $\mathrm{b}$ is denoted by:

$$
\pi(a, b)=(1 / m) \sum_{j=1}^{k} P_{j}(a, b) w_{j}
$$

$\mathbf{m}$ : criteria number, $\mathbf{P}_{\mathbf{j}}(\boldsymbol{a}, \boldsymbol{b})$ : Preference of the action a over $\mathrm{b}, \mathbf{w}_{\mathbf{j}}$ : Weight of criterion $\mathbf{j}$.

The value of the net flow determines the rank of an alternative. 


\section{PROPOSED MODEL}

The overall decisional system consists of three modules (Figure 3):

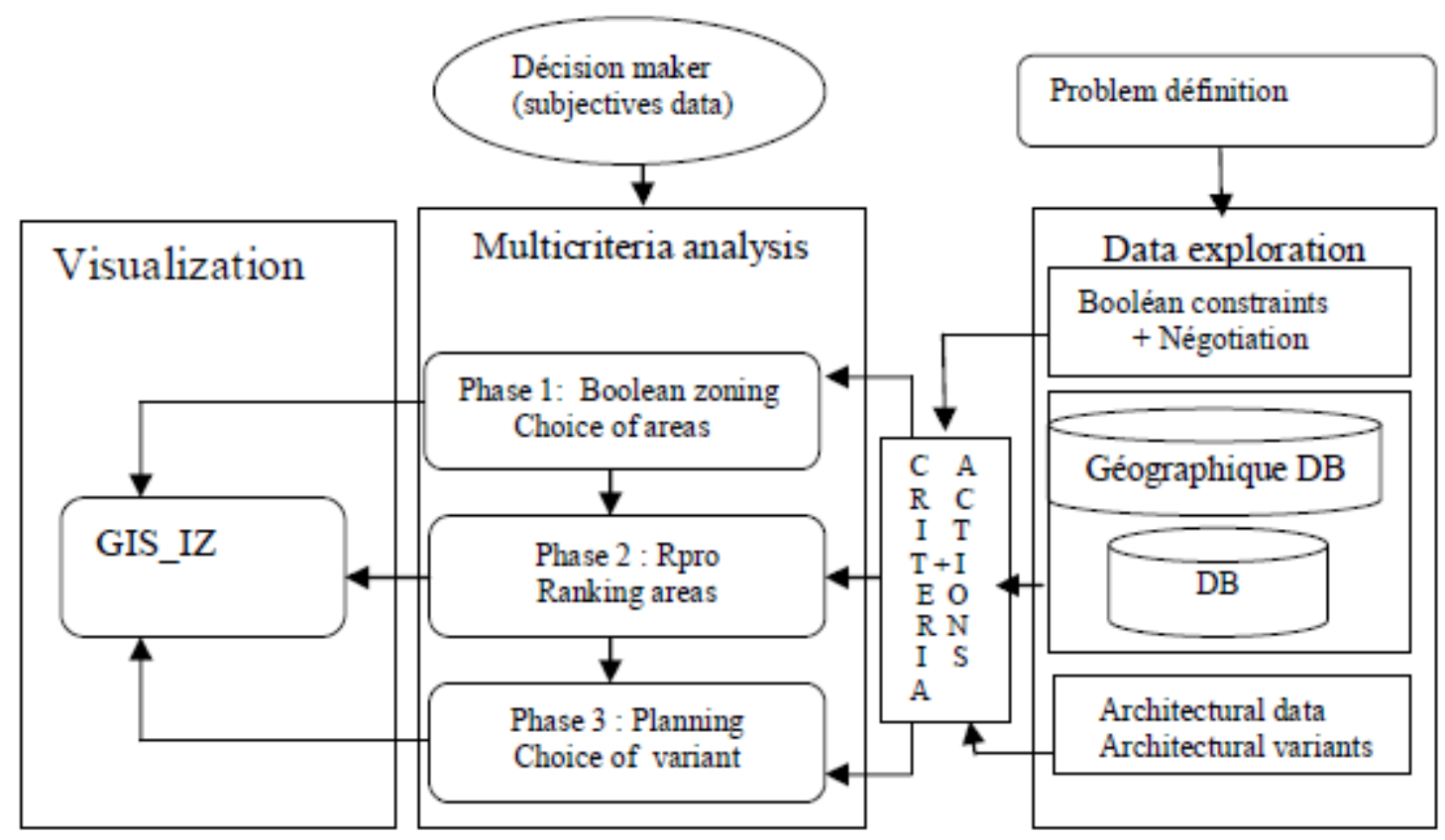

Figure 3: General System Architecture.

\subsection{The visualization module:}

Since actions in this study are all spatial, SIGZI ensures the display of these zones (actions) on the map of Algeria before and after each decision-making phase. To accomplish this task the vector mode is adopted, each industrial zone is a geographical entity of the abstract spatial type "POINT" it is implemented with geographical position (latitude and longitude).

\subsection{Data Exploration module:}

The main entities in our multi-criteria decision approach are the criteria and actions, data are collected from geographic and socioeconomic databases and from climate station as well as archives, criteria cards are built.

\subsection{The Multi-criteria analysis module:}

This is the main module for the solution of global decision problem, it operate in three phases (The aptitude study and geographical choice, ranking zones, choice of an architectural variant). Only Phase 2 (ranking zones) is explained in this paper. 


\subsubsection{First phase:}

Conducted by ANIREF [16], is a zonal aptitude analysis. Such analysis is at the heart of the processes involved in planning and is a major component of spatial decision support [6]. The Boolean zoning used belongs to the class of non-compensatory aggregation methods [8] which operates according to rules such as: If (HT electric line $>10 \mathrm{~m}$ from the zone) then (suitable zone) else (unfit zone). The ability of a zone is calculated using the intersection of several indices. $I_{A P T, j}=C_{1, j} \cap C_{2, j} \cap \ldots \cap C_{k, j}$ where $C_{k, j}$ is the aptitude binary value of the criterion $\mathrm{k}$ for the zone $\mathrm{j}$. The result is discussed, commented and complemented by negotiation.

\subsubsection{Second phase:}

It is the total ranking of zones using qualitative and quantitative values of the criteria. The total outranking method PROMETHEEII is used.

\subsubsection{Third phase:}

Consist to choose one of three available architectural variants, the selection criteria are the architecture, the management cost, the number of fragmented islands and the types of planned investments.

\section{CASe Study}

\subsection{The set of actions:}

Of the 39 industrial zones created through the entire national territory by ANIREF [16] our study has focused on the industrial areas of western Algerian. Each zone is an action (A1: Maghnia, Tlemcen. A2: Sidi Bel Abbes. A3: Ras Elma, SidiBel Abbes. A4: Sidi Ahmed, Saida. A5: Horchaia, Naama. A6: Tamazzoura, AinTémouchent. A7: Oggas Mascara . A8: El Haciane, Mostaganem. A9: Sidi Khettab, Relizane.).

\subsection{The criteria:}

The criteria used in this study were classified into three categories: natural constraints, the socioeconomic and legal requirements and environmental constraints. According to these categories, 8 different evaluation criteria are defined. Figure 4 shows the hierarchy of criteria of judgment.

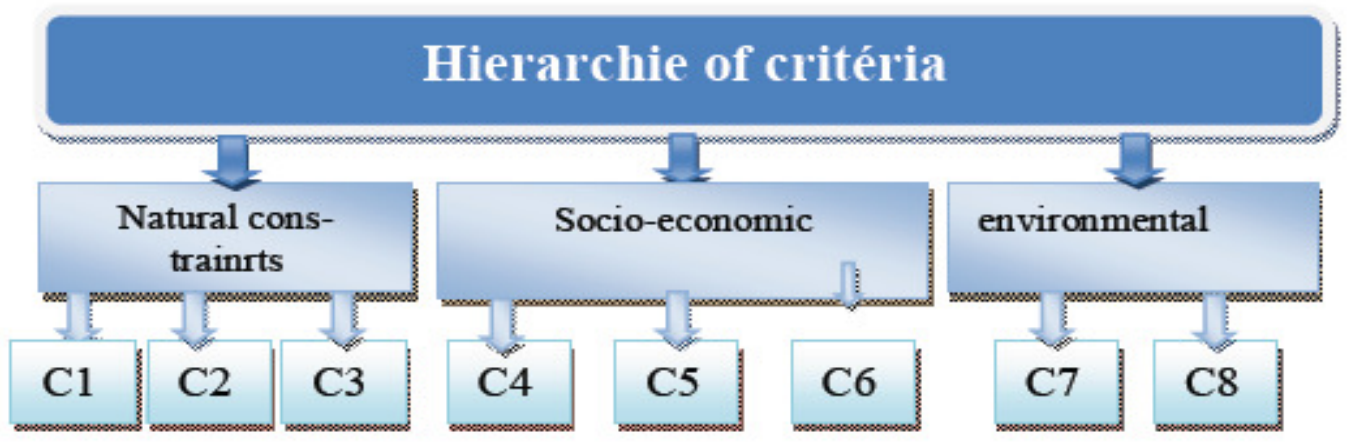

Figure 4: Hierarchy of judgment criteria. 
- Criterion (C1): Seismicity.

- Criterion (C2): Climate Constraint: Rainfall.

- Criterion (C3): Climate Constraint: Temperature.

- Criterion (C4): Surface area.

- Criterion C5): Management cost.

- Criterion (C6): Distance to transport networks.

- Criterion (C7): bioclimatic Constraint.

- Criterion (C8): Proximity to urban residential center.

To evaluate the different zones to rank on the basis of qualitative criteria, a rating scale (scale of 1 to 5 ) is associated with each qualitative criterion in order to make a measurable dimension. The principle used is to evaluate zones (actions) against the criterion on the basis of the mapping. The evaluation method is to analyze the geographical position of industrial zones on the corresponding thematic map of each geographical criterion (seismicity, humidity...).

\subsubsection{Natural constraints:}

C1-Seismicity: The seismic zoning of Algerian territory (Figure 5) reveals five seismic zones.

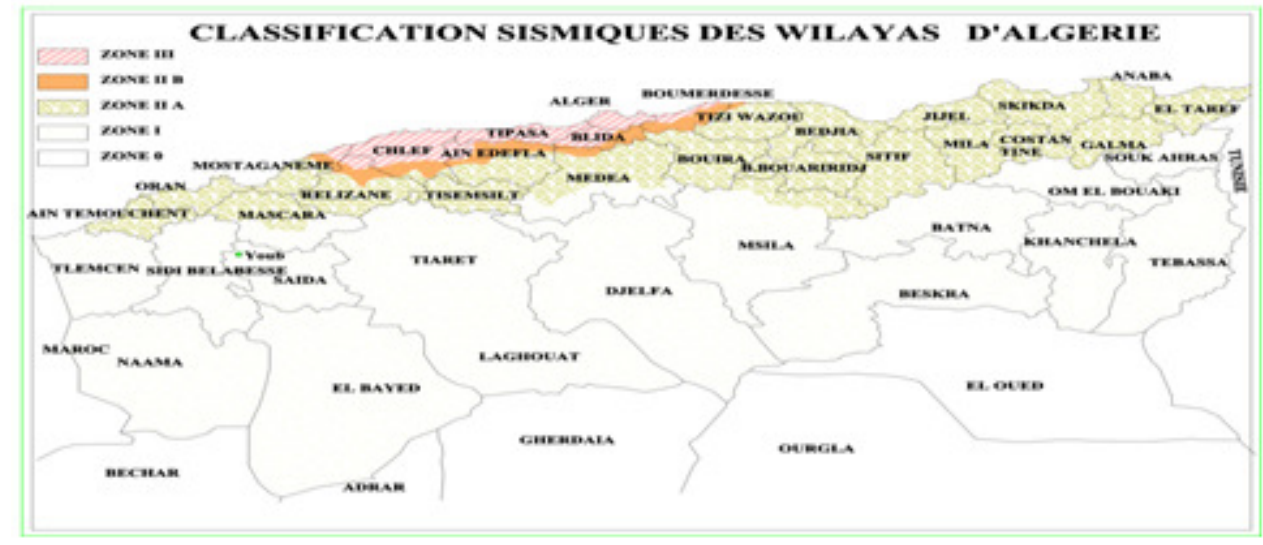

Figure 5: Seismic classification of Algeria [16].

Using the seismic map of Algeria and according to the proposed measure scale (Table 1) below contains actions values according to seismicity. 
Table1: Evaluation of the actions according to the criterion of seismicity.

\begin{tabular}{|c|c|c|}
\hline Actions & Seismicity & Numerical values \\
\hline A1 & Low to moderate & 2 \\
\hline A2 & Low to moderate & 2 \\
\hline A3 & Low to moderate & 2 \\
\hline A4 & Low to moderate & 2 \\
\hline A5 & Low & 1 \\
\hline A6 & Moderate & 3 \\
\hline A7 & Moderate & 3 \\
\hline A8 & Low to moderate & 2 \\
\hline A9 & Moderate & 2 \\
\hline
\end{tabular}

C2, C3- Climatic constraints: The average numerical values of these two criteria are taken from climate stations installed in the country.

Table2: Evaluation of the actions on criteria, rainfall and temperature

\begin{tabular}{|l|c|c|}
\hline actions & Rainfall (mm) & temperature $^{\circ} \mathbf{C}$ \\
\hline A1 & 350 & 19 \\
\hline A2 & 310 & 24 \\
\hline A3 & 410 & 17 \\
\hline A4 & 380 & 19 \\
\hline A5 & 190 & 17 \\
\hline A6 & 400 & 18 \\
\hline A7 & 320 & 21 \\
\hline A8 & 350 & 20 \\
\hline A9 & 370 & 19 \\
\hline
\end{tabular}

\subsubsection{Socio-economic criteria:}

C4: Area: This is quantitative information representing the area of each industrial zone.

C5: COST Management: This is quantitative information representing the management cost. Note that the location of the site (soil, slope, altitude ...) directly influences the lying and indirectly on the weight of this criterion.

C6 - Proximity to transport networks (roads, railway and airport): The evaluation of this criterion is done by comparing cartographically two thematic maps, the geographical situation of the zones in question with that of transport networks. 
Table 3: Evaluation according to cost management, area and proximity to transport networks.

\begin{tabular}{|l|c|c|c|}
\hline Actions & Cost planning (DA) & Area(Ha) & Proximity(m) \\
\hline A1 & 900592576 & 104 & 2500 \\
\hline A2 & 867750000 & 100 & 4100 \\
\hline A3 & 523765223 & 60 & 5000 \\
\hline A4 & 867750000 & 100 & 6500 \\
\hline A5 & 1301625000 & 150 & 3500 \\
\hline A6 & 1778911797 & 205 & 3000 \\
\hline A7 & 851772119 & 98 & 8100 \\
\hline A8 & 1735585907 & 200 & 6500 \\
\hline A9 & 4338750000 & 500 & 3000 \\
\hline
\end{tabular}

C7- environmental criteria: The map below shows the bioclimatic floors of Algeria

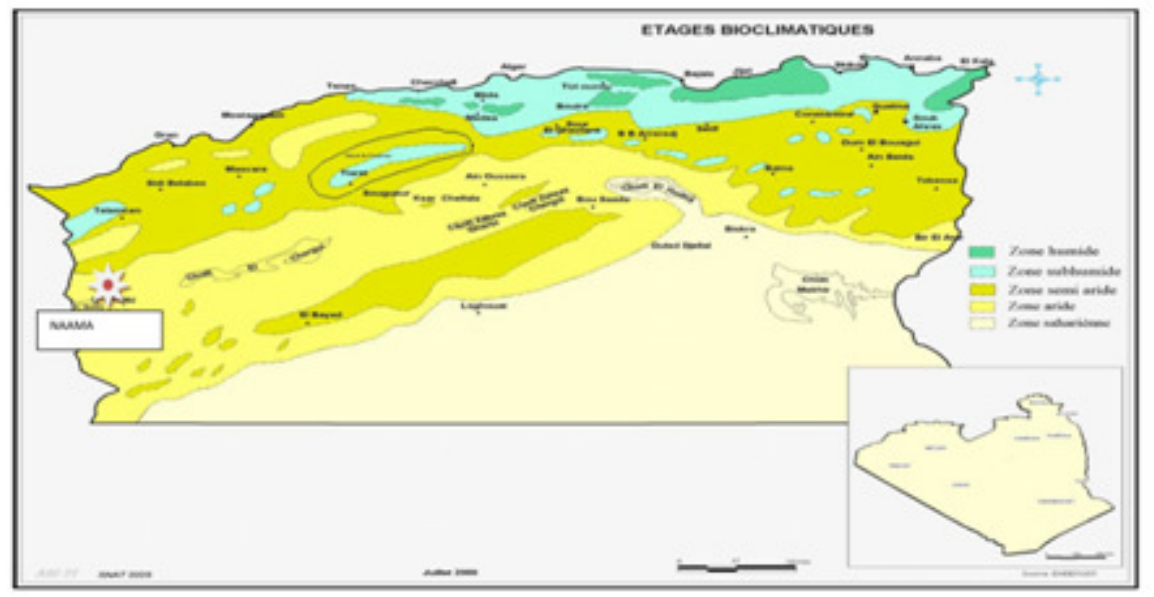

Figure 4: Bioclimatic Floors of Algeria [16].

C8: Proximity to the urban center of residence: This is the cause of noise pollution linked to increased traffic flows, propagation of harmful gases for respiratory health of citizens and liquid and solid industrial waste.

Table 4: Bioclimatic constraints and Proximity to urban centers.

\begin{tabular}{|l|l|c|c|}
\hline Actions & Description & $\begin{array}{c}\text { (Valeur Num) } \\
\text { C7 }\end{array}$ & Proximity(m) C8 \\
\hline A1 & Semi aride zone & 2 & 14000 \\
\hline A2 & Semi aride zone & 2 & 17000 \\
\hline A3 & Semi arid zone & 2 & 13500 \\
\hline A4 & Semi aride zone & 2 & 15000 \\
\hline A5 & Arid zone & 1 & 18000 \\
\hline A6 & Semi arid zone & 2 & 16500 \\
\hline A7 & Semi arid zone & 2 & 18300 \\
\hline A8 & Semi aridezone & 2 & 13000 \\
\hline A9 & Arid Zone & 1 & 17800 \\
\hline
\end{tabular}


Weights for criteria are defined by the technical team of the ANIREF [16] direction following two steps:

- Classification of the eight criteria in descending order of importance according to a unanimous decision from a consultation among all members of the team (engineers, technicians and managers).

- The second step consists of distributing a set of 100 points between the various criteria. The values of the final weights are given in Table 5:

Table 5: Table of intra criteria weights

\begin{tabular}{|c|l|c|c|}
\hline Critèria & Criteria description & weight(\%) & Weight(point) \\
\hline C1 & Seismicity. & $10 \%$ & 10 \\
\hline C2 & Climatic constraints:Rainfall & $5 \%$ & 5 \\
\hline C3 & Climatic constraints:Temperature. & $5 \%$ & 5 \\
\hline C4 & Acreage & $20 \%$ & 20 \\
\hline C5 & COST & $15 \%$ & 15 \\
\hline C6 & Proximity to transport networks & $20 \%$ & 20 \\
\hline C7 & Bioclimatic constraints & $5 \%$ & 5 \\
\hline C8 & Proximity to urban residential center & $20 \%$ & 20 \\
\hline
\end{tabular}

Note that a criterion can be a factor to maximize or a constraint to minimize. The sense of each criterion was adopted in the opinion of the expert (table6).

After the evaluation of actions, weighting criterion and determination of the sense of each criterion we obtained the following performance table (table 6)

Table 6: Performance Table

\begin{tabular}{|l|l|l|l|l|l|l|l|l|}
\hline Critèrion/Action & C1 & C2 & C3 & C4 & C5 & C6 & C7 & C8 \\
\hline A1 & 2 & 350 & 19 & 104 & 900592576 & 2500 & 3 & 14000 \\
\hline A2 & 2 & 310 & 24 & 100 & 867750000 & 4100 & 3 & 17000 \\
\hline A3 & 2 & 410 & 17 & 60 & 523765223 & 5000 & 3 & 13500 \\
\hline A4 & 2 & 380 & 19 & 100 & 867750000 & 6500 & 3 & 15000 \\
\hline A5 & 1 & 190 & 17 & 150 & 1301625000 & 3500 & 2 & 18000 \\
\hline A6 & 3 & 400 & 18 & 205 & 1778911797 & 3000 & 3 & 16500 \\
\hline A7 & 3 & 320 & 21 & 98 & 851772119 & 8100 & 3 & 18300 \\
\hline A8 & 4 & 350 & 20 & 200 & 1735585907 & 6500 & 3 & 13000 \\
\hline A9 & 3 & 370 & 19 & 500 & 4338750000 & 3000 & 2 & 17800 \\
\hline Citerion sense & Min & Min & Min & Max & Min & Min & Min & Max \\
\hline
\end{tabular}

\subsection{Result}

Although the significance of the result comes from the use of a validated method and a specific core GIS to data of the case study, remains a sensitivity analysis on preference and indifference thresholds to validate the stability of the solution. Here the indifference threshold is set at $5 \%$ of 
the difference between the highest and lowest score while the preference threshold is set at $10 \%$ of the difference. Table 8 below shows zone rows obtained.

Table 8: Obtained ranking

\begin{tabular}{|l|l|l|l|c|}
\hline Actions & $\begin{array}{c}\text { Positive flow } \\
\left(\varphi^{+}\right)\end{array}$ & $\begin{array}{c}\text { Negative flow } \\
\left(\varphi^{-}\right)\end{array}$ & Net flow $(\varphi)$ & Rank \\
\hline A1 & 0.38531917 & $0.3-$ & 0.08531916 & 4 \\
\hline A2 & 0.2971698 & 0.5250107 & -0.2278409 & 8 \\
\hline A3 & 0.36762434 & 0.35000002 & 0.017624319 & 5 \\
\hline A4 & 0.23181818 & 0.4375 & -0.20568182 & 7 \\
\hline A5 & 0.59375 & 0.2363376 & 0.3574124 & 1 \\
\hline A6 & 0.4321429 & 0.3094263 & 0.122716606 & 3 \\
\hline A7 & 0.3124035 & 0.37500003 & -0.06259653 & 6 \\
\hline A8 & 0.22386363 & 0.58466977 & -0.36080614 & 9 \\
\hline A9 & 0.5196429 & 0.24578992 & 0.27385297 & 2 \\
\hline
\end{tabular}

\subsection{Visualization:}

\subsubsection{Pre-visualization:}

Pre visualization of industrial zones on the Algerian map before the multi-criteria decision analysis, the ranks are randomly assigned (Figure 5):

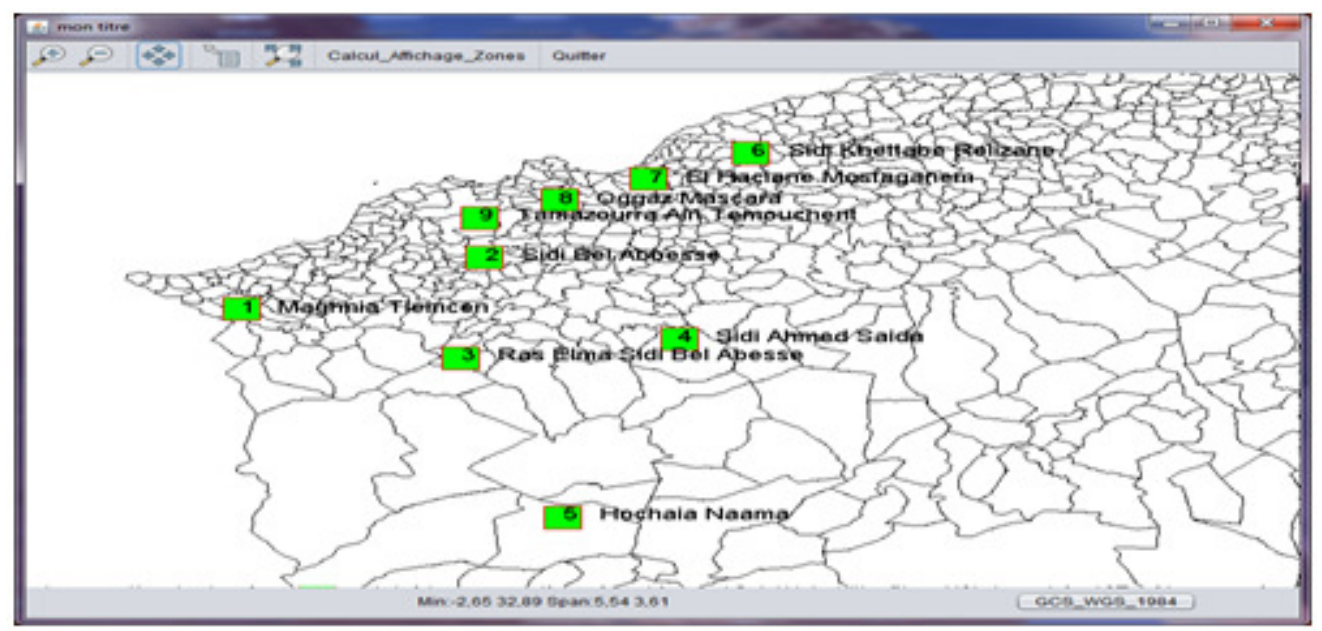

Figure 5: administrative Card with random rows.

\subsubsection{Post Visualization:}

Visualization of industrial zones on the map of Algeria after multi-criteria decision analysis with result ranks (Figure6): 


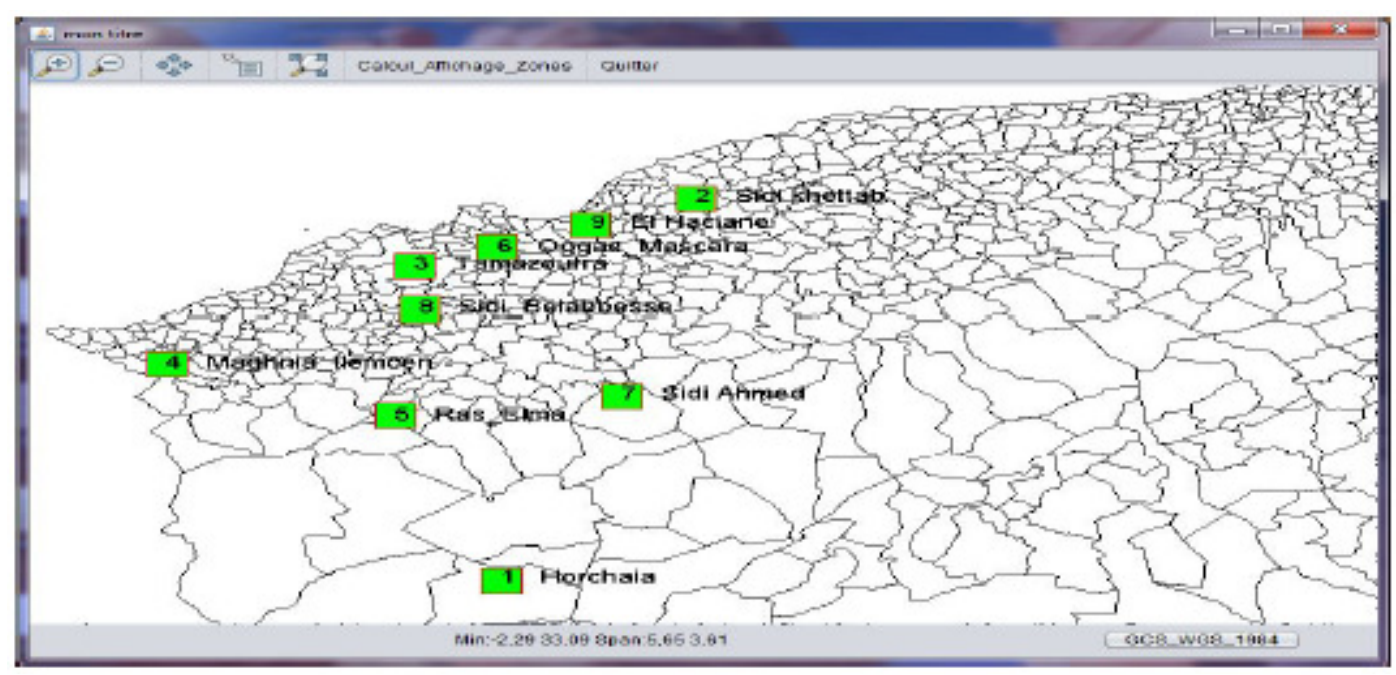

Figure 6: Viewing zone rows after the analysis.

\section{CONCLUSION AND PERSPECTIVES}

This work follows a zonal capability analysis based on Boolean non-compensatory multi-criteria methods. The constraints of selection of the zones were set by negotiation and by current legislation. The proposal in this paper is to start a second multi-criteria decision-analysis phase to consolidate those choices. The quantitative and qualitative information collected for each zone comforted the decision maker and has established a trust in him on the MCDA-GIS integration approach. This study allowed us to determine the usefulness of the approach for many sectors where the decision is important and dangerous, and intersects with the geography and even history. It is a contribution to make out the approach from the academic side to the field. The rank of an industrial area so obtained is an index that can:

- Call into question the choice of this zone.

- Alert the planners and builders of the area.

- Assign the area to adequate investment projects.

Our perspectives are to extend the study on all industrial zones at the national level which leads us to reconsider the choice of multi-criteria method. The choice of method is a crucial step, especially in our case study, four approaches can be used: Ad hoc, classification tree, multicriteria method or expert systems [4].

To remedy the disadvantage of MCDA methods in modeling the preferences of decision makers with subjectivities and hesitance we decided to follow the approach proposed by [17] to test several data mining techniques. 


\section{REFERENCES}

[1] J.P. Brans \& Ph.Vincke, (1985). A preference Ranking Organisation Method:( The PROMETHEE Method for Multiple Criteria, Management Science, Vol. 31, No.6 (Jun., 1985), PP.647-656 Published by: INFORMS.

[2] Raffaella Balzarini\&Paule-Annick Davoine \& Muriel Ney, (2012). Evolution et développement des méthodes deAnalyse spatiale multicritère pour des modèles d'aptitude : L'exemple des applications en Géosciences. Laboratoire d'Informatique de Grenoble (LIG) équipes Steamer et Metah.ESRI France, Département Education et Recherche.

[3] J.Malczewski, (2006). GIS-based multi-criteria decision analysis: a survey of the literature, International Journal of Geographical Information, 20:7, 703-726.

[4] Chakhar,Salem, (2006), Cartographie Décisionnelle Multicritère : Formalisation Et Implémentation Informatique, Thèse de doctorat, Université paris dauphine.

[5] Marc.souris (2002),Les principes de systèmes d'information géographique : Principes algorithmes et architecture du système SAVANE, These de doctorat IRD ((Institut de recherche pour le développement) France.

[6] Régis,Caloz \& Claude collet, (2011). Analyse spatiale de l'information géographique, Presse polytechniques et universitaires romandes.

[7] Fatima ZohraYounsi \& Djamila Hamdadou \& BouzianeBeldjilali, (2012). Proposition d'un Système Interactif d'Aide à la Décision Spatiale : Télédétection, SIG et Analyse Multicritère, Université d'Oran Es-Senia .

[8] Randal Greene \& Rodolphe Devillers \& Joan E.Luther \& BriaG.Eddy (2011), Gis-Based MultipleCriteria Decision Analysis Department of geography, Memorial University of New-foundland, Canadian Forest service, Natural resources Canada. Geography compass 5/6.

[9] Balali, Banafsheh Zahraie \& Abbas Roozbahani, A Comparison of AHP and PROMETHEE Family Decision Making Methods for Selection of Building Structural System, American Jour-nal of Civil Engineering and Architecture, vol. 2, no. 5 (2014): 149-159.

[10] Valentina Ferretti \& Silvia Pomarico, integrating Multicriteria Analysis and Geographic In-formation Systems for studying ecological corridors in the Piedmont Region, 74th Meeting of the European Working Group "Multiple Criteria Decision Aiding".

[11] S'habou R \& ,Zairi M \& Kallel A\& Neji J. Ben Dhia H, (2011).Intégration du SIG et des méthodes d'analyse multicritère pour la gestion de la pollution: cas de stockage des margines Sfax Tunisie, Séminaire International, Innovation \& Valorisation en Genie civil \& Materiaux de construction, Rabat Maroc: INVACO2 Nº $5 \mathrm{O}-309$.

[12] L. Pugnet \& E.Maillé, (2013).Analyse multicritères pour l'évaluation de la vulnérabilité des interfaces habitat-foret, international conference on forest «fire risk modelling and mapping » Aix en Provence, France.

[13] Carlo,Prévil \& Marius,Thériault \& Joël.Rouffignat, (2003).Analyse multicritère et SIG pour faciliter la concertation en aménagement du territoire : vers une amélioration du processus décisionnel. Les Cahiers de géographie du Québec, p. 35-61, Nº 130 : Vol.. 47. 
[14] Vazquez Maria \& L. WAAUB \& Jean-Philippe CHAUMEL\& Jean-Louis (2011), Analyse spa-tiale et approche d'aide multicritères et multi-acteurs à la négociation pour évaluer des scéna-rios d'implantation des parcs éoliens, publié dans "1ère Conférence Intercontinentale d'Intelli-gence Territoriale Interdisciplinarité dans l'aménagement et développement des territoires", Gatineau : Canada.

[15] J-Pierre Brans \& Bertrand Mareschal, PROMETHEE METHODS Centrum voor Statistiek en Operationeel Onderzoek Vrije Universiteit Brussel Pleinlaan 2, B-1050 Brussels\& Service de Mathématiques de la Gestion Université Libre de Bruxelles Boulevard du Triomphe CP 210-01, B1050 Brussels Belgium .

[16] ANIREF (Agence Nationale d'Intermédiation et de REgulation Fonciére) (2013). Etude preliminaire d'amenagement du parc industriel . Alger.

[17] Kary Frakling (1996), Modélisation et apprentissage des préférences par réseaux de neurones pour l'aide à la décision multicritère. Thèse doctorat, Ecole nationale des mines de Saint-Etienne.

[18] B.Roy, (1985), Méthodologie multicritère d'aide à la décision, Paris Economica.

[19] B.taibi (2010) , L' analyse multicritère comme outil d'aide à la décision Aplication de la methode PROMETHEE etude de cas:l'entreprise SEROR, These de Magister ,Université de Tlemcen, Algerie.

[20] Deliverable 4B, (2010). Multi-criteria analysis and ranking of alternative waste technologies/ management system, Rapport de recherche, Faculté des sciences Eljadida, National technical university of Athens, Municipality of the urban community of Azemmour, Maroc.

[21] Egenhofer M.J A, (1989), Formal Definition of Binary Topological Relationships, Proceedings of the 3th International Conference on Foundations of data Organization and Algorithms. - Paris, France Lecture Notes in Computer Science 367, 1989. - pp. 457-472 .

[22] H.Laurent, (2000). Systémes d'évaluation et de classification multicritères pour l'aide à la décision. Thése de doctorat Université Paris Dauphin .

[23] Pugnet L. et E.Maillé, (2013). La modélisation et la cartographie des risques de forets, International conférence on Forest risk modelling and mapping.

[24] S,BenMena, (2000). Introduction aux méthodes multicritères d'aide à la décision, B A S E Biotechnol. Agron. Soc. Environ.Unité de Mathématique. Faculté universitaire des Sciences agronomiques de Gembloux.

[25] Michel grabisc (2004), Une approche constructive de la décision multicritère, manuscrit Uni-versité Paris I.

[26] Gregory A. Kiker\& Todd S. Bridges\& Arun Varghese\& Thomas P. Seager, \& Igor Linkov (2005), Application of Multi-criteria Decision Analysis in Environmental Decision Making, Integrated Environmental Assessment and Management - Volume 1, Number 2 - pp. 95-108. 


\section{AUTHORS}

Aissa Taibi is a Ph.D. student and assistant professor at Oran University and affiliated researcher in Oran computer Lab. He is engineer in computer systems from Oran University in 1987; he received the Magister degree in system modelization from the same university in 2003. His interest field is Multi-criteria decision analysis and geographic information systems, expert systems and fuzzy reasoning.

Baghdad Atmani received his Ph.D. degree in computer science from the University of Oran (Algeria), in 2007. He is full professor in computer science. His interest field is knowledge discovery from data and his research are directed towards the Machine Learning problems. His research is based on inductive machine learning approaches, knowledge systems based and case-based reasoning. His research are guided and evaluated through various applications in the field of control systems, scheduling, production, maintenance, simulation, data integration and spatial data-mining. 